\title{
Von der Seelenblindheit
}

\author{
Enrico Danieli \\ Dr. med., Facharzt für Allgemeine Innere Medizin, Mitglied FMH
}

Hat die Seele als Zentrum unseres Seins keine Funktion mehr? Ist meine Seele, wie es heisst, tatsächlich krank, wenn ich vom Gefühl des Unverständnisses (mir gegenüber) nicht loskomme? Behandeln mich so wie früher Seelenärzte? Ist ihre Spezialität (noch immer) die Seelenkunde? Oder ist das Bewusstsein, die Fähigkeit zur Besinnung, an die Stelle der Seele getreten? Ein Wort, das allerdings besser in seiner negativen Form verstanden wird: die Bewusstlosigkeit. Der Geist, ohne Zweifel, hat schon lange ausgedient; er ist zu sehr mit Glauben - der Geistliche, Geistheiler usw. - belastet, obwohl geistreich oder geistesgegenwärtig oder geistvoll von Klugheit spricht und geisteskrank (noch immer) von Krankheit. Und die Psyche? Heute für alles zuständig, kaum je gesund und weniger denn je fassbar. In der griechischen Mythologie sinnigerweise die Geliebte des Amor, also Eros, sie bedeutet Hauch, Atem, Leben und deswegen Seele, inkonsistent, transparent, bewegt. Heute korreliert der Begriff Psyche, definitionsgemäss die Summe aus bewusst und unbewusst, mehr mit Zuordnungen und Unterzuordnungen, mit einem Adaptations- oder Lernkonzept. Laut umformulierter Gesundheitsdefinition besteht seelische und körperliche Gesundheit in der Fähigkeit, sich an neue Gegebenheiten anzupassen: die Kunst zur Mimikry! Weil ich diese Kunst (im Seelischen) nicht beherrsche, bin ich (vielleicht) zu recht geistig angeschlagen, wie es heisst. Und doch sitzt eine Seele in meinem Kopf: ist die Seelenheilkunde - einst (und vielleicht auch heute noch) die Psychiatrie - eine medizinisch untergeordnete Handlangerin der Effektiven, der Nützlichen, der Brauchbaren geworden, derjenigen, die mittels Funktionalitätszuordnungen Wissen vom Hirn suggerieren, das viel mit Studien, Analysen, Experten und wenig mit Patienten zu tun hat? Trotz täglich sich ändernden Behauptungen zu neuen Seeleneinsichten. Die Seele, sie ist es, die als Inbegriff der bewussten und mehr noch der unbewussten (nicht erklärbaren) Hirnvorgänge einsteht für Empfindungen, für das Fühlen, für das Erleben, das Erinnern, für das Leben. Entsprechend den früheren Denkern könnte es eine mehr wahrnehmende, erinnernde, erlebende Seele geben und eine mehr denkende, analysierende (geistige). Natürlich arbeitet an diesen Überschneidungen und Klärungen die Psychiatrie, die Psychologie und alle die ih- nen zugewandten wissenden oder weniger wissenden Orte, doch es scheint, als wäre unser heutiges Wissen in keiner Weise mehr in der Lage, sich unter einem Dach zu versammeln. Ein sich stetig vermehrendes Wissen setzt sich der Gefahr aus, in Einzelteile zu zerfallen. Der Patient wird in den Tausenden von (stets) wissenschaftlichen Schnittstellen verloren gehen. So wie im All verschollen. Ungehört, unverstanden, schliesslich ungesehen, endlich vergessen.

Seelenblindheit erkennt reale Gegenstände nicht (Seelentaubheit hört nicht) - die Erkrankung lokalisiert sich in der Gehirnrinde. Eine Form der Agnosie, eine gestörte Wahrnehmung von Sinnesreizen - notabene: die Agnostiker, eine Lehre der alten Griechen, vertraten die Meinung, einen Sinn des Daseins, des Lebens, gebe es nicht (so wie es Gott nicht gebe). Eine visuelle Amnesie? Das genaue Sehen aber ist die Voraussetzung für die Wahrnehmung. Und das Sehen ist Voraussetzung für das Erkennen. Wir wissen: Psycho heisst auch Seele, ein komplexes Wortelement, gleichzeitig meint es das Gemüt. Er ist gemütskrank, er ist seelisch angeschlagen, es ist alles nur psychisch, er soll geisteskrank sein - die Begriffe vermischen sich. Alles, wie wir erkennen, hängt mit allem zusammen. Wahrgenommen wird nur das, was erlernt wurde, wahrgenommen zu werden, nur das, das sich domestizieren lässt (das die Arbeit nicht verkompliziert), wahrgenommen wird nur das, was den vorhandenen Strukturen entspricht, was eingeordnet werden kann, was ins Bild passt. Ist das, was nicht gehört werden will, ist das, was nicht gesehen werden will, ist das, was nicht verstanden werden will, auch eine Form von Agnosie? "Alles, was Sie sagen, ergibt doch keinen Sinn!» Ein mir wohlbekannter Satz. So kann meine Wahrnehmung auch nicht sein. Meine Therapeuten hörten/hören nur das, was sie hören, sehen, verstehen wollen, aber das, was auch zu mir gehört, mich leitet, mich bestimmt, das sehen sie nicht. Das ergibt in ihrem erlernten System, ihrer Seelennorm, eben keinen Sinn. Oder sind es meine Sinne, die irren? Nein, denn: Sie alle und noch viel mehr von ihnen sind blind, sie sind Seelenblinde, obwohl Seelenspezialisten. Oder gerade deswegen? «Was ist das Schwerste von allem? Was dir das Leichteste dünket: Mit den Augen zu sehen, was vor den Augen dir liegt» (Goethe). 